\title{
A few important clinical trials in cardiac surgery, which have influenced management
}

\author{
Mohd Shahbaaz Khan* \\ Cardiac Surgeon, Department of Cardiac Surgery, King Fahad Medical City, Riyadh, Kingdom of Saudi Arabia
}

\section{Introduction}

There are some important clinical trials, which have changed the management strategies for the cardiac diseases patients.

Here are a few trials worth mentioning as they have revolutionized the management strategies in cardiac surgeries.

\section{A prospective randomized clinical study of thyroid hormone treatment after operations for complex congenital heart disease.}

This trial was done by Devyani Chowdhury, MD, Kaie Ojamaa, $\mathrm{PhD}$, Vincent A. Parnell, MD, Claire McMahon, MD, Cristina P. Sison, $\mathrm{PhD}$, and Irwin Klein, MD, Manhasset, NY and was published in The Journal of Thoracic and Cardiovascular Surgery, 2001 Nov, Volume 122, Number 5, 1023-1025 [1].

\section{Method}

- 75 consecutive patients were selected (between the ages of birth and 18 years).

- Criteria for the treatment arm was serum total T3 level of less than $40 \mathrm{ng} / \mathrm{dL}$ (or $<60 \mathrm{ng} / \mathrm{dL}$ for newborns) on postoperative days 0,1 , or 2 and a requirement for mechanical ventilation.

- T3 treatment group received continuous T3 infusion at the rate of $0.05-0.15 \mu \mathrm{g} / \mathrm{kg}$ of bodyweight/ hour to maintain serum levels within the normal range (80-200 ng/dL).

\section{Results}

- 28 of 75 patients were eligible for the study, with 14 patients randomized to $\mathrm{T} 3$ treatment.

- Lowest values were measured after 24 and 48 hours.

- T3 treatment significantly decreased the need for inotropic support, lower mean daily inotropic score of $5 \pm 3$ compared with $23 \pm 26(\mathrm{P}=0.037)$ in the untreated group.

- At 18 to 24 hours, the mean MVO2 increased to $70 \% \pm 12 \%$ in the T3-treated group and remained unchanged at $44 \% \pm 18 \%$ in the untreated group.

\section{Conclusion}

This study concluded that T3 had therapeutic benefits in the postoperative period by using a continuous infusion protocol to normalize serum T3 levels in new-born patients undergoing operations for complex congenital heart disease.

\section{Mechanical methods of reducing blood transfusion in cardiac surgery: randomized controlled trial}

This trial was done by Neil McGill, Denise O'Shaughnessy, Ruth Pickering, Mike Herbertson, Ravi Gill and was published in British Medical Journal. Jun 1, 2002; 324(7349): 1299 [2].

\section{Objective}

Its objective was to assess the effectiveness of two mechanical methods of blood conservation in reducing the need for allogeneic red blood cells or coagulation products during cardiac surgery.

\section{Methods}

- It was a randomized controlled trial performed at Regional cardiac centre in a teaching hospital in Southampton.

- 263 adults (18-80 years of age) undergoing elective coronary artery bypass surgery were selected

- 252 adults completed the trial.

- Three treatment groups were made:

1) intraoperative cell salvage.

2) intraoperative cell salvage with acute perioperative normovolaemic haemodilution.

3) No mechanical blood conservation.

- There were 84 patients in each group.

\section{Results}

- Patients in the intraoperative cell salvage group, 26 were given a transfusion of allogeneic blood, compared with 43 in the control group [odds ratio 0.43 ( $95 \%$ confidence interval 0.23 to 0.80 )].

- Mean number of units of allogeneic blood transfused per patient in the intraoperative cell salvage group was 0.68 units $(\mathrm{SD}=1.55)$, compared with 1.07 (1.56) units in the control group.

- $\quad 32$ of the patients in the intraoperative cell salvage group were given any blood product, compared with 47 in the control group [odds ratio 0.47 ( 0.25 to 0.89$)$; $\mathrm{P}=0.019$ ].

Correspondence to: Mohd Shahbaaz Khan, Cardiac Surgeon, Department of Cardiac Surgery, King Fahad Medical City, Riyadh, Kingdom of Saudi Arabia, Tel: +919716062389; E-mail: mohdshahbaazkhan@yahoo.com

Received: September 28, 2016; Accepted: October 11, 2016; Published: October 13, 2016 
- Combining acute perioperative normovolaemic haemodilution with intraoperative cell salvage conferred no additional benefits.

\section{Conclusion}

This trial concluded that: Intraoperative cell salvage device can be used in elective coronary artery bypass grafting

- Pharmacological strategies may further reduce requirements of blood transfusions.

- $\quad$ Further reductions in blood transfusions could be achieved if the lower safe limit of haemoglobin concentration in patients undergoing cardiac surgery were known.

Intravenous sildenafil and inhaled nitric oxide: a randomized trial in infants after cardiac surgery

This trial was done by Christian Stocker, Daniel J. Penny, Christian P. Brizard, Andrew D. Cochrane, Rodrigo Soto, Lara S. Shekerdemian and was published in Intensive Care Medicine November 2003, Volume 29, Issue 11, pp 1996-2003 [3].

\section{Objective}

Its objective was to investigate the acute effects of intravenous sildenafil on haemodynamics and oxygenation, and its interaction with inhaled nitric oxide (iNO) in infants at risk of pulmonary hypertension early after cardiac surgery.

\section{Method}

- This was a prospective randomized trial and was performed at paediatric intensive unit of a children's hospital.

- 16 ventilated infants (after closure of VSD or AVSD) were randomized to one of two groups.

- The study was completed in 15 infants.

- Studies were commenced within 7hrs of separation from bypass.

- 7 infants received iNO (20 ppm) first then addition of $\mathrm{i} / \mathrm{v}$ sildenafil $(0.35 \mathrm{mg} / \mathrm{kg}$ over $20 \mathrm{~min})$ after $20 \mathrm{~min}$.

- 8 infants received sildenafil first then iNO was added after $20 \mathrm{~min}$.

- Vascular pressures, cardiac output and a blood gas were recorded at 0,20 and $40 \mathrm{~min}$.

\section{Results}

- In infants receiving iNO first, iNO lowered the pulmonary vascular resistance index (PVRI) from 3.45 to 2.95 units $(p=0.01$ ); sildenafil further reduced PVRI to 2.45 units $(p<0.05)$.

- In those receiving sildenafil first, PVRI was reduced from 2.84 to 2.35 units $(p<0.05)$ with sildenafil, and fell to 2.15 units $(p=$ $0.01)$ with the addition of iNO.

- In both groups, sildenafil reduced the systemic blood pressure and systemic vascular resistance $(p<0.01)$ and worsened arterial oxygenation and the alveolar-arterial gradient $(p<0.05)$.

\section{Conclusion}

This trial concluded that: Intravenous sildenafil augmented the pulmonary vasodilator effects of iNO in infants early after cardiac surgery.

- $\quad$ Sildenafil produced systemic hypotension and impaired oxygenation, which was not improved by iNO.

\section{Albumin versus crystalloid for pump priming in cardiac surgery: meta-analysis of controlled trials}

This trial was done by James A. Russell, MD, Roberta J. Navickis, $\mathrm{PhD}$, and Mahlon M. Wilkes, $\mathrm{PhD}$ and was published in Journal of Cardiothoracic and Vascular Anesthesia 2004; 18(4): 429-437 [4].

\section{Objectives}

Its objective was to determine the effects of pump priming fluid choice on platelets, fluid balance, and clinical outcomes.

\section{Interventions}

Extracorporeal circuit priming was done with either albumin or crystalloid.

\section{Methods}

- This was meta- analysis of controlled clinical trials.

- The meta-analysis included 21 controlled trials with 1,346 total patients.

\section{Results}

- Albumin prime significantly reduced the on-bypass drop in platelet counts.

- The pooled weighted mean difference in platelet count drop with albumin versus crystalloid prime was $-23.8 \times 10(9) / \mathrm{L}$ (confidence interval [CI], -42.8 to $-4.7 \times 10(9) / \mathrm{L})$.

- The colloid oncotic pressure decline was also smaller when albumin rather than crystalloid was used for priming, with a pooled weighted mean difference of $-3.6 \mathrm{~mm} \mathrm{Hg}(\mathrm{CI},-4.8$ to $-2.3 \mathrm{mmHg}$ ) during bypass and $-2.0 \mathrm{mmHg}(\mathrm{CI},-2.9$ to $-1.1 \mathrm{mmHg}$ ) after surgery.

- Albumin prime correspondingly reduced on-bypass positive fluid balance $(-584 \mathrm{~mL}$; CI, -819 to $-348 \mathrm{~mL}$ ) and postoperative weight gain $(-1.0 \mathrm{~kg}$; CI, -0.6 to $-1.3 \mathrm{~kg})$ compared with crystalloid.

- Postoperative colloid usage was lower with albumin than crystalloid prime (-612 mL; CI, -983 to $-241 \mathrm{~mL}$ ).

\section{Conclusions}

This trial concluded that: Albumin prime better preserved platelet counts than crystalloid

- Albumin also favorably influences colloid oncotic pressure, on-bypass positive fluid balance, postoperative weight gain, and colloid usage.

\section{Fresh frozen plasma in the pediatric pump prime: a} prospective, randomized trial

This trial was done by Mary M. McCall, MSN, Mindy M. Blackwell, MS, Jonathan T. Smyre, MS, Joseph J. Sistino, MPA, Jeffrey R. Acsell, BS, B. Hugh Dorman, MD, PhD, And Scott M.Bradley, MD and was Published In Ann Thorac Surg. 2004 Mar; 77(3): 986-7; discussion 987 [5]. 


\section{Background}

The aim of this study was to determine whether the use of fresh frozen plasma (FFP) in the infant pump prime can avoid dilution of fibrinogen, decrease the need for blood product transfusion after bypass, and decrease exposure to donor blood products.

\section{Methods}

- $\quad$ Twenty infants weighing less than $8 \mathrm{~kg}$ were prospectively randomized to receive either $1 \mathrm{U}$ of FFP (10 patients) or no FFP (10 patients) in the pump prime.

- Mean age $(4.2 \pm 2.8$ months $)$, weight $(4.3 \pm 1.1 \mathrm{~kg})$, total prime volume $(641 \pm 96 \mathrm{ml})$, cardiopulmonary bypass time, cross-clamp time, lowest temperature on bypass, and preoperative coagulation parameters did not differ between the two groups.

\section{Results}

- At the end of bypass, the mean fibrinogen level was significantly higher in the FFP than the no FFP group (123 \pm 20 versus $58 \pm 17 \mathrm{mg} / \mathrm{dL} ; \mathrm{p}<0.0001)$

- Whereas the mean platelet count did not differ $(60 \pm 25$ versus $52 \pm 26 \mathrm{~K} / \mathrm{mm}(3) ; \mathrm{p}=0.5)$

- Patients in the FFP group received significantly fewer units of cryoprecipitate $(0.4 \pm 0.8$ versus $2.0 \pm 0.9 \mathrm{U} /$ patient; $\mathrm{p}<0.001$ and had a mean total donor exposure of $4.1 \pm 1.5 \mathrm{U} /$ patient versus $5.4 \pm 1.4$ $\mathrm{U} /$ patient in the no FFP group $(\mathrm{p}=0.06)$.

- The mean chest tube output over the first 24 hours did not differ between groups (Table 1).

\section{Conclusions}

This trial concluded that: The use of FFP in the pump prime significantly limited dilutional hypofibrinogenemia, decreased the transfusion of cryoprecipitate after bypass, and tended to decrease the overall mean patient exposure to blood products.

\section{A randomized, double-blind, placebo-controlled pilot trial of triiodothyronine in neonatal heart surgery}

This trial was done by Andrew S. Mackie, MD, SM, Karen L. Booth, MD, Jane W. Newburger, MD, MPH, Kimberlee Gauvreau, ScD, Stephen A. Huang, MD, Peter C. Laussen, MBBS, James A. DiNardo, MD, Pedro J. del Nido, MD, PhD, John E. Mayer, Jr, MD, Richard A. Jonas, MD, Ellen McGrath, RN, Jodi Elder, RN, and Stephen J. Roth, MD, MPH and was published in The Journal of Thoracic and Cardiovascular Surgery, September 2005, Volume 130, Number 3, 810$816[6]$.

\section{Objective}

This study was undertaken to evaluate the effect of triiodothyronine replacement on the early postoperative course of neonates undergoing aortic arch reconstruction.

\section{Methods}

- They performed a randomized, double-blind, placebocontrolled trial of triiodothyronine supplementation in neonates undergoing either a Norwood procedure or two-ventricle repair of interrupted aortic arch and ventricular septal defect.

- Patients were assigned to receive a continuous infusion of triiodothyronine $(0.05 \mu / \mathrm{kg} / \mathrm{h})$ or placebo for 72 hours after cardiopulmonary bypass.

- $\quad$ Primary end points were a composite clinical outcome score and cardiac index at 48 postoperative hours.

\section{Results}

- They enrolled 42 patients (triiodothyronine $\mathrm{n}=22$, placebo $\mathrm{n}=20)$.

- Baseline characteristics were similar in the treatment groups.

- Study drug was discontinued prematurely because of hypertension $(n=1)$ and ectopic atrial tachycardia $(n=1)$, both cases in the triiodothyronine group.

- $\quad$ Free and total triiodothyronine levels were higher in the triiodothyronine group than in the placebo group at 24,48 , and 72 postoperative hours $(P<0.001)$

- The median clinical outcome scores were 2.0 (range 0-4) with triiodothyronine and 2.0 (range $0-7)$ with placebo $(P=0.046)$

- Compared with those in the placebo group, neonates assigned to triiodothyronine had shorter median time to negative fluid balance ( 2.0 vs 2.5 days, $P=0.027$ )

- Cardiac index values were $2.11 \pm 0.64 \mathrm{~L} / \mathrm{min} \cdot \mathrm{m}^{2}$ with triiodothyronine and $2.05 \pm 0.72 \mathrm{~L} / \mathrm{min} \cdot \mathrm{m}^{2}$ with placebo $(P=0.81)$.

- Heart rate and diastolic blood pressure were not influenced by triiodothyronine supplementation, but systolic blood pressure was higher in the triiodothyronine group $(P<0.001)$.

- No serious adverse events were attributed to triiodothyronine administration.

\section{Conclusion}

This trial concluded that: Triiodothyronine supplementation was safe and resulted in more rapid achievement of negative fluid balance after aortic arch reconstruction

- Cardiac index at 48 hours was not significantly improved.

Systematic review of randomized controlled trials of therapeutic hypothermia as a neuroprotectant in post cardiac arrest patients

This trial was done by Ka Wai Cheung, MD, Robert S. Green, BSc, MD, Kirk D. Magee, MD, MSc and was published in Canadian Journal of Emergency Medicine 2006; 8(5): 329-337 [7].

\section{Objective}

- Several randomized controlled trials had suggested that mild induced hypothermia may improve neurologic outcome in comatose cardiac arrest survivors

- This systematic review of randomized controlled trials was designed to determine if mild induced hypothermia improves neurologic outcome, decreases mortality, or is associated with an increased incidence of adverse events.

\section{Data Sources}

The following databases were reviewed:

Cochrane Controlled Trials Register (Issue 4, 2005) 
MEDLINE (January 1966 to November 2005)

EMBASE (1980 to November 2005)

CINAHL (1982 to November 2005)

Web of Science (1989 to November 2005)

For each included study, references were reviewed and the primary author contacted to identify any additional studies.

\section{Methods}

- Studies that met inclusion criteria were randomized controlled trials of adult patients ( $>18$ years of age) with primary cardiac arrest who remained comatose after return of spontaneous circulation.

- Patients had to be randomized to mild induced hypothermia $\left(32^{\circ} \mathrm{C}-34^{\circ} \mathrm{C}\right)$ or normothermia within 24 hours of presentation.

- Only studies reporting pre-determined outcomes including discharge neurologic outcome, mortality or significant treatmentrelated adverse events were included.

- There were no language or publication restrictions.

Results

- $\quad$ Four studies involving 436 patients were included.

- 232 cooled to a core temperature of $32^{\circ} \mathrm{C}-34^{\circ} \mathrm{C}$ met inclusion criteria.

- $\quad$ Pooled data demonstrated that mild hypothermia decreased in-hospital mortality (relative ratio [RR] $0.75 ; 95 \%$ confidence interval [CI], 0.62-0.92) and reduced the incidence of poor neurologic outcome (RR 0.74; 95\% CI, 0.62-0.84).

- Numbers needed to treat were 7 patients to save 1 life, and 5 patients to improve neurologic outcome.

- There was no evidence of treatment-limiting side effects.

\section{Conclusions}

This trial concluded that: Therapeutically induced mild hypothermia decreases in-hospital mortality and improves neurologic outcome in comatose cardiac arrest survivors.

- The possibility of treatment-limiting side effects cannot be excluded.

\section{Bosentan therapy in patients with eisenmenger syndrome: a multicenter, double-blind, randomized, placebo-controlled study}

This trial was done by Andrea Lauer, Eleonora Chiossi and Michael Landzberg, Nazzareno Galiè, Maurice Beghetti, Michael A. Gatzoulis, John Granton, Rolf M.F. Berger, and published in Circulation. 2006; 114(1):48-54 [8].

\section{Background}

- Eisenmenger syndrome is characterized by the development of pulmonary arterial hypertension with consequent intracardiac rightto-left shunt and hypoxemia in patients with pre-existing congenital heart disease.

- Because Eisenmenger syndrome is associated with increased endothelin expression, patients may benefit from endothelin receptor antagonism.
- Theoretically it is thought that interventions that have some effect on the systemic vascular bed could worsen the shunt and increase hypoxemia.

\section{Methods}

- The Bosentan Randomized Trial of Endothelin Antagonist Therapy-5 (BREATHE-5) was a 16-week, multicenter, randomized, double-blind, placebo-controlled study.

- This evaluated the effect of bosentan, a dual endothelin receptor antagonist, on systemic pulse oximetry (primary safety end point) and pulmonary vascular resistance (primary efficacy end point) in patients with World Health Organization functional class III Eisenmenger syndrome.

- Hemodynamics were assessed by right- and left-heart catheterization.

- Secondary end points included exercise capacity assessed by 6 -minute walk distance, additional hemodynamic parameters, functional capacity, and safety.

\section{Results}

- $\quad$ Fifty-four patients were randomized 2:1 to bosentan $(n=37)$ or placebo $(\mathrm{n}=17)$ for 16 weeks.

- The placebo-corrected effect on systemic pulse oximetry was $1.0 \%$ (95\% confidence interval, -0.7 to 2.8 ), demonstrating that bosentan did not worsen oxygen saturation.

- Compared with placebo, bosentan reduced pulmonary vascular resistance index (-472.0 dyne.s.cm $(-5) ; \mathrm{P}=0.0383)$.

- The mean pulmonary arterial pressure decreased $(-5.5 \mathrm{~mm}$ Hg; $\mathrm{P}=0.0363$ ).

- The exercise capacity increased (53.1 m; $\mathrm{P}=0.0079)$.

- $\quad$ Four patients discontinued as a result of adverse events, 2 (5\%) in the bosentan group and $2(12 \%)$ in the placebo group.

\section{Conclusions}

This trial concluded that: In this first placebo-controlled trial in patients with Eisenmenger syndrome, bosentan was well tolerated and improved exercise capacity and hemodynamics without compromising peripheral oxygen saturation.

\section{The effect of hematocrit during hypothermic cardiopulmonary bypass in infant heart surgery: Results from the combined Boston hematocrit trials}

This trial was done by David Wypij, PhD, Richard A. Jonas, MD, David C. Bellinger, PhD, MSc, Pedro J. Del Nido, MD, John E. Mayer, Jr., MD, Emile A. Bacha, MD, Joseph M. Forbess, MD, Frank Pigula, MD, Peter C. Laussen, MD and Jane W. Newburger, MD, MPH and was published in The Journal of Thoracic and Cardiovascular Surgery Volume 135, Issue 2, February 2008, Pages 355-360 [9].

\section{Objective}

- Two randomized trials of hematocrit strategy during hypothermic cardiopulmonary bypass in infant heart surgery had been performed

- The first suggested worse outcomes were concentrated in 
patients with lower hematocrit levels (approximately 20\%), whereas the second suggested there was little benefit to increasing the hematocrit level above $25 \%$

- The form of the relationship between continuous hematocrit levels and outcomes required further study.

\section{Methods}

- In the two trials, 271 infants who underwent biventricular repair not involving the aortic arch were enrolled.

- Analysis was undertaken of the effects of hematocrit level, as a continuous variable, at the onset of low-flow cardiopulmonary bypass.

\section{Results}

- $\quad$ Psychomotor Development Index scores at age 1 year varied non linearly with haematocrit levels, with increasing scores up to $23.5 \%$ hematocrit $(P<0.001)$ and a plateau effect beyond $23.5 \%(P=0.42)$.

- Lower hematocrit levels were associated with more positive intraoperative fluid balance $(P<0.001)$ and higher serum lactate levels at 60 minutes after bypass $(P=0.08$ for linear trend $)$.

- Each 1-point increase in hematocrit up to $23.5 \%$ was associated with a 2.6-point increase in PDI scores (95\% CI 1.1-4.2; P $=0.001)$.

- $\quad$ increasing hematocrit level above $23.5 \%$, there was no significant increase in PDI scores (slope $0.2,95 \%$ CI $0.8-0.3 ; P=0.42$ )

\section{Conclusions}

This trial concluded that: A hematocrit level at the onset of low-flow cardiopulmonary bypass of approximately $24 \%$ or higher is associated with higher Psychomotor Development Index scores and reduced lactate levels.

- $\quad$ Because the effects of hemodilution may vary according to diagnosis, age at operation, bypass variables such as $\mathrm{pH}$ strategy and flow rate, and other perioperative factors, this study cannot ascertain a universally "safe" hemodilution level.

\section{Randomized trial of hematocrit $25 \%$ versus $35 \%$ during hypothermic cardiopulmonary bypass in infant heart surgery}

This trial was done by Jane W. Newburger, MD, MPH, Richard A. Jonas, MD, Janet Soul, MD, Barry D. Kussman, MBBCh, David C. Bellinger, $\mathrm{PhD}, \mathrm{MSc}$, Peter C. Laussen, MD, Richard Robertson, MD, John E. Mayer Jr, MD, Pedro J. del Nido, MD, Emile A. Bacha, MD, Joseph M. Forbess, MD, Frank Pigula, MD, Stephen J. Roth, MD, $\mathrm{MPH}$, Karen J. Visconti, PhD, Adre J. du Plessis, MBChB, MPH, David M. Farrell, MA, CCP, Ellen McGrath, RN, Leonard A. Rappaport, $\mathrm{MD}$, and David Wypij, $\mathrm{PhD}$ and published in J Thorac Cardiovasc Surg. 2008 Feb;135(2):347-54, 354.e1-4 [10].

\section{Objectives}

- They had previously reported that postoperative hemodynamics and developmental outcomes were better among infants randomized to a higher hematocrit value during hypothermic cardiopulmonary bypass.

- However, worse outcomes were concentrated in patients with hematocrit values of $20 \%$ or below, and the benefits of hematocrit values higher than $25 \%$ were uncertain.

\section{Methods}

- $\quad$ They compared perioperative hemodynamics and at 1 year, developmental outcome and brain magnetic resonance imaging in a single-center, randomized trial of hemodilution to a hematocrit value of $25 \%$ versus $35 \%$ during hypothermic radiopulmonary bypass for reparative heart surgery in infants undergoing 2-ventricle repairs without aortic arch obstruction.

\section{Results}

- A total of 124 subjects, 56 were assigned to the lowerhematocrit strategy $(24.8 \% \pm 3.1 \%$, mean \pm SD) and 68 to the higherhematocrit strategy $(32.6 \% \pm 3.5 \%)$.

- Infants randomized to the $25 \%$ strategy, compared with the $35 \%$ strategy, had a more positive intraoperative fluid balance $(P=$ $0.007)$ and lower regional cerebral oxygen saturation at 10 minutes after cooling $(P=0.04)$ and onset of low flow $(P=0.03)$.

- Infants with dextro-transposition of the great arteries in the $25 \%$ group had significantly longer hospital stay. Other postoperative outcomes, blood product usage, and adverse events were similar in the treatment groups.

- At age 1 year $(\mathrm{n}=106)$, the treatment groups had similar scores on the Psychomotor and Mental Development Indexes of the Bayley Scales; both groups scored significantly worse than population norms.

\section{Conclusions}

This trial concluded that: Hemodilution to hematocrit levels of $35 \%$ compared with those of $25 \%$ had no major benefits or risks overall among infants undergoing 2 -ventricle repair.

- Developmental outcomes at age 1 year in both randomized groups were below those in the normative population.

\section{Early extubation and weaning with bilevel positive airway pressure ventilation after cardiac surgery}

This trial was done by Abdullah KILIC, Nihan YAPICI, Yesim BICER, Turkan CORUH, Arif TARHAN*, Fikri YAPICI*, Zuhal AYKAC Siyami Ersek and was published in South African Journal of Anaesth Analg:2008, volume 14, number 5, 25-31 [11].

\section{Background}

Thistrialwasdonetoevaluatetheuseofbilevelpositiveairwaypressure (BiPAP) ventilation in early extubation after fast-track cardiac surgery. Methods

- Sixty consecutive patients eligible for early extubation after cardiac surgery were randomly assigned to pressure supportcontinuous positive airway pressure or BiPAP (Group I or Group II, respectively) and were extubated.

- Blood gases and hemodynamics were determined on arrival in the ICU (baseline) and 1, 2, 4, 6, 8, and 12 hours later.

- $\quad$ All data were expressed as $( \pm$ SD) and analyzed using the Student t-test and Mann-Whitney test (continuous data) or $\chi^{2}$ test.

- $\quad \mathrm{P}<0.05$ was considered statistically significant. 


\section{Results}

- $\quad \mathrm{PaCO}_{2}$ levels were statistically significantly higher in Group II than in Group I at 2, 4, 6, 8, and 12 hours $(\mathrm{P}<0.05, \mathrm{P}<0.01)$.

- Within each group, PaCO2 levels were statistically significantly higher at 4, 6, 8, and 12 hours than at baseline $(\mathrm{P}<0.01)$.

- $\quad$ Extubation time was significantly longer in Group I than in Group II 7.90 (7.90 [2.13] vs 3.83 [1.20], P = 0.001).

- $\quad$ Respiratory rates were significantly higher in Group II than in Group I after 2, 4, and 6 hours $(\mathrm{P}<0.01)$.

\section{Conclusions}

This trial concluded that: Early extubation and weaning to BiPAP ventilation after cardiac surgery is safe and effective.

\section{A randomized trial of outcomes of anesthetic management directed to very early extubation after cardiac surgery in children}

This trial was done by Preisman, MD, Henrietta Lembersky, MD, Yakov Yusim, MD, Lisa Raviv-Zilka, MD, Azriel Perel, MD, Ilan Keidan, MD, and David Mishaly, $\mathrm{MD}$ and was published in $\mathrm{J}$ Cardiothoracic Vascular Anesthesia. 2009 Jun; 23(3):348-57 [12].

\section{Objectives}

- Intraoperative management directed to early extubation of children undergoing cardiac surgery had been suggested as a viable alternative to prolonged postoperative mechanical ventilation.

- The authors evaluated the safety and efficacy of this approach in a randomized prospective trial.

\section{Participants}

- $\quad$ One hundred consecutive pediatric patients (age 1 month-15 years, weight $3.0-51 \mathrm{~kg}$ ) requiring cardiac surgery were included.

- $\quad$ Patients younger than 1 month of age and those requiring mechanical ventilation before the operation were considered ineligible for the study.

\section{Interventions}

- $\quad$ Patients were randomly allocated to a group with anesthetic management and extubation in the operating room (early group [EG]) and a group with elective prolonged mechanical ventilation (control group $[\mathrm{CG}])$.

\section{Methods}

- $\quad$ A difference in outcome as reflected by the pediatric intensive care unit (PICU) and hospital lengths of stay and postoperative morbidity and mortality was analysed.

- A separate analysis was performed in children younger than 3 years old.

\section{Results}

- The extubation time in the CG was $25.0 \pm 26.9$ hours.

- No differences in mortality, the need for re-exploration for bleeding, the need for reintubation, the incidence of abnormal chest radiographic findings, or cardiac and septic complications between groups were found
- $\quad$ PICU and postoperative hospital lengths of stay were significantly shorter in patients in the EG $(3.3 \pm 1.9$ days in the EG v $5.8 \pm 4.1$ in the CG, $\mathrm{p}<0.001$, and $7.4 \pm 2.9$ days in the EG v $11.2 \pm 6.8$ days in the CG, $\mathrm{p}=0.009$ ).

\section{Conclusions}

This trial concluded that: In children undergoing cardiac surgery, anesthetic management with early cessation of mechanical ventilation appears to be safe and decreases hospital and PICU length of stay.

Efficacy and economic assessment of conventional ventilatory support versus extracorporeal membrane oxygenation for severe adult respiratory failure (CESAR): a multicentre randomised controlled trial

This trial was done by Giles J Peek MD, Prof Miranda Mugford DPhil, Ravindranath Tiruvoipati FRCSE, Prof Andrew Wilson MD, Elizabeth Allen PhD, Mariamma M Thalanany MSc, Clare L Hibbert $\mathrm{PhD}$, Ann Truesdale BSc, Felicity Clemens MSc, Nicola Cooper PhD, Richard K Firmin MBBS, Prof Diana Elbourne PhD and this was published in journal The Lancet, Volume 374, Issue 9698, Pages 1351 - 1363, 17 October 2009 [13].

\section{Background}

- Severe acute respiratory failure in adults causes high mortality despite improvements in ventilation techniques and other treatments (eg, steroids, prone positioning, bronchoscopy, and inhaled nitric oxide).

- Their aim was to delineate the safety, clinical efficacy, and cost-effectiveness of extracorporeal membrane oxygenation (ECMO) compared with conventional ventilation support.

\section{Methods}

- They had randomly assigned 180 adults in a 1:1 ratio (continued conventional management or ECMO).

- $\quad$ Aged 18-65 years and had severe (Murray score $>3.0$ or $\mathrm{pH}$ $<7.20$ ) but potentially reversible respiratory failure.

- $\quad$ Exclusion criteria $=$ high pressure $(>30 \mathrm{~cm} \mathrm{H} 2 \mathrm{O}$ of peak inspiratory pressure).

-High $\mathrm{FiO}_{2}(>0 \cdot 8)$ ventilation for more than 7 days.

-Intracranial bleeding.

-Contraindication to heparinisation.

-Any contraindication to continuation of active treatment.

\section{Results}

- $68(75 \%)$ patients received ECMO.

- $63 \%$ (57/90) of patients (ECMO group) survived to 6 months without disability compared with $47 \%(41 / 87)$ of conventional management (RR 0.69; 95\% CI 0.05-0.97, p = 0.03).

- Referral to consideration for treatment by ECMO treatment led to a gain of 0.03 quality-adjusted life-years (QALYs) at 6-month follow-up.

\section{Conclusion}

This trial concluded that: ECMO-based management protocol for 
adult patients with severe but potentially reversible respiratory failure, whose Murray score exceeds 3.0 or who have a pH of less than 7.20 on optimum conventional management, significantly improved survival without severe disability.

Early extubation after pediatric cardiac surgery: systematic review, meta-analysis, and evidence-based recommendations

This review study was done by Alghamdi AA, Singh SK, Hamilton BC, Yadava M, Holtby H, Van Arsdell GS, Al-Radi OO and was published in Journal Card Surgery. 2010 Sep; 25(5):586-95 [14].

\section{Objective}

Its objective was to derive evidence-based recommendations regarding early extubation strategy after congenital cardiac surgery.

\section{Evidence}

Medline, Embase, and the Cochrane-controlled trial register on the Cochrane library were searched from the earliest achievable date of each database to present

Retrieved reprints were evaluated according to prior inclusion criteria, and those included were critically appraised using established internal validity criteria.

\section{Methods}

- $\quad$ Paediatric patients ( $<18$ years) were included

- Paediatric cardiac surgical procedure (with or without cardiopulmonary bypass)

- Early extubation strategy was extubation in the operating room or within six hours after surgery

- Control group of patients were extubated more than six hours after surgery.

\section{Results}

- Twenty-three studies were included in the review

- Nine were eligible for meta-analysis ( $n=2,014$ patients; range 36 to 1,000$)$.

- One was a Randomized Control Trial ( $\mathrm{n}=100$ patients),

- Seven were retrospective case control studies $(n=914$ patients)

- One was a retrospective cohort study ( $\mathrm{n}=1,000$ patients).

- $\quad$ Early extubation was associated with significantly improved in-hospital mortality rates compared with control (RR 0.1, 95\% CI 0.01 to $0.84 ; \mathrm{n}=1,233$ patients),

\section{Conclusion}

This trial concluded that: Early extubation appears safe and is associated with reduction in length of ICU and hospital stay without adverse effects on mortality or morbidity.

\section{Randomized, controlled trial of individualized heparin and protamine management in infants undergoing cardiac surgery with cardiopulmonary bypass}

This trial was done by Colleen E. Gruenwald, MHSC, RN, CCP,
CPC, Cedric Manlhiot, BSC, Anthony K. Chan, MD, Lynn CrawfordLean, BSC, RRT, CCP, CPC, Celeste Foreman, BA, CCP, CPC, Helen M. Holtby, MB BS, Glen S. Van Arsdell, MD, Ross Richards, PHD, Helen Moriarty, BAPPSC, MAPPSC, Brian W. McCrindle, MD, MPH and published in J Am Coll Cardiol. 2010 Nov 23; 56(22):1794-802 [15].

\section{Objectives}

They wanted to determine whether infants (< 1-year-old) had similar clinical benefits with individualized anticoagulation management as older children and adult undergoing cardiopulmonary bypass $(\mathrm{CPB})$.

\section{Methods}

- Ninety infants ( $<1$ year of age) undergoing CPB were enrolled in a randomized controlled trial comparing weight-based anticoagulation management using activated clotting time (ACT) to individualized management with Hemostasis Management System.

- Manufacturer's guidelines were followed for the first 33 patients.

- A modified protocol was used for the last 57 patients with adjustments for coagulation system immaturity and hemodilution on $\mathrm{CPB}$.

\section{Results}

- The hemostasis management system (HMS) device consistently underestimated plasma anti-Xa levels, leading to an overestimated required heparin dose.

- After a blinded interim analysis revealed poor outcomes in the experimental HMS group using manufacturer guidelines, the safety committee suspended the study pending protocol modifications.

- The use of the HMS device following the modified protocol resulted in more stable anti-Xa levels during CPB with improved postoperative outcomes including reduced need for transfusions $(71 \mathrm{ml} /$ $\mathrm{kg}$ vs. $80 \mathrm{ml} / \mathrm{kg} ; \mathrm{p}=0.003$ ), ventilation time ( $33 \mathrm{~h}$ vs. $49 \mathrm{~h} ; \mathrm{p}=0.04)$, intensive care ( $88 \mathrm{~h}$ vs. $99 \mathrm{~h} ; \mathrm{p}=0.003)$, and hospital length of stay (192 $\mathrm{h}$ vs. $216 \mathrm{~h} ; \mathrm{p}<0.001)$, compared with the weight-based protocol.

\section{Conclusions}

This trial concluded that: This study supported the use of the HMS device, with a modified protocol for infants younger than 1 year of age, for anticoagulation management during $\mathrm{CPB}$

- Clinical guidelines for the use of the HMS device should be modified for infants younger than 1 year of age.

\section{Safety of recombinant activated factor VII in randomized clinical trials}

This clinical trial was done by Marcel Levi, M.D., Jerrold H. Levy, M.D., Henning Friis Andersen, M.Sc., and David Truloff, D.V.M. and was published in N Engl J Med. 2010; 363(19):1791-800 [16].

\section{Background}

- The use of recombinant activated factor VII (rFVIIa) on an off-label basis to treat life-threatening bleeding had been associated with a perceived increased risk of thromboembolic complications.

- However, data from placebo-controlled trials were needed to 
properly assess the thromboembolic risk.

- To address this issue, they evaluated the rate of thromboembolic events in all published randomized, placebocontrolled trials of rFVIIa used on an off-label basis.

\section{Methods}

- $\quad$ They analyzed data from 35 randomized clinical trials (26 studies involving patients and 9 studies involving healthy volunteers) to determine the frequency of thromboembolic events.

- The data were pooled with the use of random-effects models to calculate the odds ratios and $95 \%$ confidence intervals.

\section{Results}

- 4468 subjects were included (4119 patients and 349 healthy volunteers),

- 401 had thromboembolic events $(9.0 \%)$.

- $\quad$ Rates of arterial thromboembolic events among all 4468 subjects were higher among those who received rFVIIa than those who received placebo $(5.5 \%$ vs. $3.2 \%, \mathrm{P}=0.003)$.

- Rates of venous thromboembolic events were similar in those who received rFVIIa and who received placebo (5.3\% vs. 5.7\%).

- $\quad$ Coronary arterial thromboembolic events $2.9 \%$ in subjects received $\mathrm{rFVII}$, as compared with $1.1 \%$ who received placebo $(\mathrm{P}=$ $0.002)$.

- Rates of arterial thromboembolic events at or $>65$ years of age were higher in subjects received rFVIIa than among subjects who received placebo, $(9.0 \%$ vs. $3.8 \%, \mathrm{P}=0.003)$

\section{Conclusions}

This trial concluded that: In a large and comprehensive cohort of persons in placebo-controlled trials of rFVIIa, treatment with high doses of rFVIIa on an off-label basis significantly increased the risk of arterial but not venous thrombo embolic events, especially among the elderly. (Funded by Novo Nordisk.).

\section{Protective effects of steroids in cardiac surgery: a meta- analysis of randomized double-blind trials}

This trial was done by Giangiuseppe Cappabianca, MD, Crescenzia Rotunno, BSc, Luigi de Luca Tupputi Schinosa, MD, V. Marco Ranieri, MD, and Domenico Paparella, MD and was published in J Cardiothorac Vasc Anesth. 2011 Feb; 25(1):156-65 [17].

\section{Objective}

- Cardiac surgery and cardiopulmonary bypass (CPB) induce an acute inflammatory response contributing to postoperative morbidity

- The use of steroids as anti-inflammatory agents in surgery using CPB has been tested in many trials and has been shown to have good anti-inflammatory effects but no clear clinical advantages for the lack of an adequately powered sample size

- The aim of this study was to evaluate the effects of steroid treatment on mortality and morbidity after cardiac surgery.

\section{Methods}

- This was a systematic meta-analysis of randomized double- blind trials (RDBs) and included adult patients who underwent cardiac surgery.

- A trial search was performed through PubMed and Cochrane databases from 1966 to January 2009.

- Among 104 clinical trials reviewed, 31 RDB trials (1,974 patients) were considered suitable to be analyzed

- A quality assessment of the trials was performed using the Jadad score.

- The types of steroid used in these trials were methylprednisolone (51.4\%), dexamethasone (34.3\%), hydrocortisone (5.7\%), prednisolone (2.9\%), or a combination of methylprednisolone and dexamethasone (5.7\%).

\section{Results}

- $\quad$ Steroid prophylaxis provided a protective effect preventing postoperative atrial fibrillation (odds ratio $=0.56$; confidence interval [CI] 0.44-0.72, $\mathrm{p}<0.0001$ ), reducing postoperative blood loss (mean difference $=-204.2 \mathrm{~mL}$; CI from -287.4 to $-121 \mathrm{~mL} ; \mathrm{p}<0.0001$ ), and reducing intensive care unit (mean difference $=-6.6$ hours; $\mathrm{CI}$ from -10.5 to -2.7 hours, $p=0.0007$ ) and overall hospital stay (mean difference $=-0.8$ days; $\mathrm{CI}$ from -1.4 to -0.2 days, $\mathrm{p}=0.01$ )

- Steroid prophylaxis had no effect on postoperative mortality, mechanical ventilation duration, re-exploration for bleeding, and postoperative infection.

\section{Conclusions}

This trial concluded that: A systematic review of RDB trials reveals that steroid prophylaxis may reduce morbidity after cardiac surgery and does not increase the risk of postoperative infections.

A multicenter, randomized trial comparing heparin/ warfarin and acetylsalicylic acid as primary thromboprophylaxis for 2 years after the fontan procedure in children

This trial was performed by Paul Monagle, MD, MSC, MBBS, Andrew Cochrane, MD, Robin Roberts, MSC, Cedric Manlhiot, BSC, Robert Weintraub, MBBS, Barbara Szechtman, BA, Marina Hughes, DPHIL, Maureen Andrew, MD, Brian W. McCrindle, MD, MPH, for the Fontan Anticoagulation Study Group and was published in Journal of the American College of Cardiology, Volume 58, Issue 6, 2 August 2011, Pages 652-653 [18].

\section{Objectives}

The purpose of this study was to compare the safety and efficacy of acetylsalicylic acid (ASA) and warfarin for thromboprophylaxis after the Fontan procedure.

\section{Background}

- Fontan surgery is the definitive palliation for children with single-ventricle physiology.

- Thrombosis was an important complication; the optimal thromboprophylaxis strategy had not been determined.

\section{Methods}

- This was a multicenter international randomized trial of primary prophylactic anticoagulation after Fontan surgery. 
- $\quad$ Patients were randomized to receive for 2 years either ASA $(5 \mathrm{mg} / \mathrm{kg} /$ day, no heparin phase) or warfarin (started within $24 \mathrm{~h}$ of heparin lead-in; target international normalized ratio: 2.0 to 3.0 ).

- Primary endpoint (intention to treat) was thrombosis, intracardiac or embolic (all events adjudicated)

- At 3 months and 2 years after the Fontan procedure, transthoracic and transesophageal echocardiograms were obtained as routine surveillance

- Major bleeding and death were primary adverse outcomes.

\section{Results}

- A total of 111 eligible patients were randomized (57 to ASA, 54 to heparin/warfarin).

- Baseline characteristics for each group were similar.

- There were 2 deaths unrelated to thrombosis or bleeding.

- There were 13 thromboses in the heparin/warfarin group ( 3 clinical, 10 routine echo) and 12 thromboses in the ASA group (4 clinical, 8 routine echo).

- Overall freedom from thrombosis 2 years after Fontan surgery was $19 \%$, despite thrombosis prophylaxis.

- Cumulative risk of thrombosis was persistent but varying and similar for both groups $(\mathrm{p}=0.45)$.

- Major bleeding occurred in 1 patient in each group.

\section{Conclusions}

This trial concluded that: There was no significant difference between ASA and heparin/warfarin as primary thromboprophylaxis in the first 2 years after Fontan surgery.

- Thrombosis rate was suboptimal for both regimens, suggesting alternative approaches should be considered. (International Multi Centre Randomized Clinical Trial of Anticoagulation in Children Following Fontan Procedures; NCT00182104).

\section{Effect of tranexamic acid on blood loss in pediatric cardiac surgery: a randomized trial}

This trial was done by Kazuyoshi Shimizu, Yuichiro Toda, Tatsuo Iwasaki, Mamoru Takeuchi, Hiroshi Morimatsu, Moritoki Egi, Tomohiko Suemori, Satoshi Suzuki, Kiyoshi Morita, Shunji Sano and was published in J Anesth. 2011 Dec; 25(6):823-830 [19].

\section{Background}

- The benefit of tranexamic acid (TXA) in pediatric cardiac surgery on postoperative bleeding had varied among studies.

- It was also unclear whether the effects of TXA differ between cyanotic patients and acyanotic patients

- The aim of this study was to test the benefit of TXA in pediatric cardiac surgery in a well-balanced study population of cyanotic and acyanotic patients.

\section{Methods}

- A total of 160 pediatric patients undergoing cardiac surgery with cardiopulmonary bypass ( 81 cyanotic, 79 acyanotic) were included in this single-blinded, randomized trial at a tertiary care university- affiliated teaching hospital

- Eighty-one children (41 cyanotic, 40 acyanotic) were randomly assigned to a TXA group, in which they received $50 \mathrm{mg} / \mathrm{kg}$ of TXA as a bolus followed by $15 \mathrm{mg} / \mathrm{kg} / \mathrm{h}$ infusion and another $50 \mathrm{mg} /$ $\mathrm{kg}$ into the bypass circuit

- The other 79 patients were randomly assigned to a placebo group. The primary end point was the amount of 24 -h blood loss.

\section{Results}

- The amount of 24-h blood loss was significantly less in the TXA group than in the placebo group [mean (95\% confidence interval): $18.6(15.8-21.4)$ vs. $23.5(19.4-27.5) \mathrm{ml} / \mathrm{kg}$, respectively; mean difference $-4.9(-9.7$ to -0.01$) \mathrm{ml} / \mathrm{kg} ; \mathrm{p}=0.049]$.

- This effect of TXA was already significant at $6 \mathrm{~h}[9.5$ (7.5$11.5)$ vs. $13.2(10.6-15.9) \mathrm{ml} / \mathrm{kg}$, respectively; mean difference -3.47 $(-7.0$ to -0.4$) \mathrm{ml} / \mathrm{kg} ; \mathrm{p}=0.027]$.

- There was no significant difference in the amount of blood transfusion between the groups.

- There was also no statistical difference in the effect of TXA in each cyanotic and acyanotic subgroup (Table 2)

\section{Conclusion}

\section{This trial concluded that}

TXA can reduce blood loss in pediatric cardiac surgery but not the transfusion requirement (http://ClinicalTrials.gov numberNCT00994994).

\section{Effect of normothermic cardiopulmonary bypass on renal injury in pediatric cardiac surgery: A randomized controlled trial}

This trial was done by Massimo Caputo, MD, Nish Patel, FRCS, Gianni D. Angelini, FRCS, Paolo de Siena, MD, Serban Stoica, FRCS, Andrew J. Parry, FRCS, and Chris A. Rogers, $\mathrm{PhD}$ and was published in The Journal of Thoracic and Cardiovascular Surgery, Volume 143, Issue 3, March 2012, Page 758 [20].

\section{Objective}

- Although hypothermic cardiopulmonary bypass (CPB) is associated with a reduction in oxygen requirement but it has a number of disadvantages including detrimental effects on enzymatic function, energy generation, and cellular integrity.

- Normothermic perfusion is potentially a more physiologic method to maintain the functional integrity of major organ systems.

- One of the aims of this trial was to compare the effect of normothermic and hypothermic $\mathrm{CPB}$ on renal injury in pediatric patients undergoing cardiac surgery.

\section{Methods}

- 59 children were included (median age 78 months; range, 39-130).

- $\quad$ Randomized to either hypothermic $\left(28^{\circ} \mathrm{C}\right)$ or normothermic $\left(35^{\circ} \mathrm{C}-37^{\circ} \mathrm{C}\right) \mathrm{CPB}$.

- Urinary albumin, retinal binding protein (RBP) and $\mathrm{N}$-acetyl-b-glucosaminidase (NAG) were measured preoperatively, 
end of $\mathrm{CPB}, 4$, and 24 hours postoperatively and were expressed as a ratio of urinary creatinine.

- $\quad$ Serum creatinine was measured preoperatively, end of $\mathrm{CPB}$, and 24 and 48 hours postoperatively.

\section{Results}

- Serum creatinine $(-2.10 ; 95 \%$ confidence interval [CI], -6.51-2.31), RBP (ratio, 0.96; 95\%CI, 0.65-1.41), and NAG (ratio, 0.86; $95 \% \mathrm{CI}, 0.56-1.36)$ were similar in the 2 groups $(\mathrm{P} \geq 0.34$ ),

- Urinary albumin was significantly lower in the normothermic group (ratio, 0.63; 95\% CI, 0.42-0.95, $\mathrm{P}=0.03$ ).

\section{Conclusions}

This trial concluded that: Normothermic CPB is associated with similar renal impairment to hypothermic $\mathrm{CPB}$ in children undergoing heart surgery.

\section{Tight glycemic control versus standard care after pediatric cardiac surgery}

This study was done by Michael S.D. Agus, M.D., Garry M. Steil, Ph.D., David Wypij, Ph.D., John M. Costello, M.D., M.P.H., Peter C. Laussen, M.B., B.S., Monica Langer, M.D., Jamin L. Alexander, B.A., Lisa A. Scoppettuolo, M.S., Frank A. Pigula, M.D., John R. Charpie, M.D., Ph.D., Richard G. Ohye, M.D., and Michael G. Gaies, M.D., M.P.H., and was published in New England Journal of Medicine on September 7, 2012 [21].

\section{Background}

- In some studies, tight glycemic control with insulin improved outcomes in adults undergoing cardiac surgery, but these benefits were unproven in critically ill children at risk for hyperinsulinemic hypoglycaemia.

- They tested the hypothesis that tight glycemic control reduces morbidity after pediatric cardiac surgery.

\section{Methods}

- This was two-centered, prospective, randomized trial.

- They enrolled 980 children (0-36 months of age) undergoing surgery with cardiopulmonary bypass.

- $\quad$ Patients were randomly assigned to either tight glycemic control (with the use of an insulin-dosing algorithm targeting a blood glucose level of 80 to $110 \mathrm{mg}$ per deciliter [4.4 to $6.1 \mathrm{mmol}$ per liter]) or standard care in the cardiac intensive care unit (ICU).

- Continuous glucose monitoring was used to guide the frequency of blood glucose measurement and to detect impending hypoglycaemia.

- Primary outcome was the rate of health care-associated infections in the cardiac ICU. Secondary outcomes included mortality, length of stay, organ failure, and hypoglycemia.

\section{Results}

- $444 / 490$ children assigned too tight glycemic control (91\%) received insulin.

- $\quad 9 / 490$ children assigned to standard care (2\%).
- Normoglycemia was achieved earlier with tight glycemic control than with standard care ( 6 hours vs. 16 hours, $\mathrm{P}<0.001$ ) and was maintained for a greater proportion of the critical illness period ( $50 \%$ vs. $33 \%, \mathrm{P}<0.001)$.

- But tight glycemic control was not associated with a significantly decreased rate of health care-associated infections (8.6 vs. 9.9 per 1000 patient-days, $\mathrm{P}=0.67$ ).

- Secondary outcomes did not differ significantly between groups, and tight glycemic control did not benefit high-risk subgroups.

- $\quad$ Only 3\% of the patients assigned too tight glycemic control had severe hypoglycemia (blood glucose $<40 \mathrm{mg}$ per deciliter [2.2 mmol per liter]).

\section{Conclusions}

This trial concluded that: Tight glycemic control can be achieved with a low hypoglycemia rate after cardiac surgery in children, but it does not significantly change the infection rate, mortality, length of stay, or measures of organ failure, as compared with standard care. (Funded by the National Heart, Lung, and Blood Institute and others; SPECS ClinicalTrials.gov number, NCT00443599).

\section{The myocardial protective effects of a moderate- potassium blood cardioplegia in pediatric cardiac surgery: a randomized controlled trial}

This trial was done by Yang Liu, MD, PhD, Sheng-li Zhang, MD, $\mathrm{PhD}$, Wei-xun Duan, MD, PhD, Lan-ping Lei, MD, Shi-qiang Yu, $\mathrm{MD}, \mathrm{PhD}$, Xin-hong Qian, MD, and Zhen-xiao Jin, $\mathrm{MD}, \mathrm{PhD}$ and was published in Ann Thorac Surg. 2012 Oct;94(4):1295-301 [22].

\section{Background}

They investigated the myocardial protective effect of a moderatepotassium cold blood cardioplegic solution $(\mathrm{K}+, 10 \mathrm{mmol} / \mathrm{L})$ in pediatric cardiac surgery.

\section{Methods}

- 2 groups were made- high potassium cold blood cardioplegia and low potassium cold blood cardioplegia.

- $\quad$ Sixty-eight pediatric patients with congenital heart disease were randomly allocated to the high potassium $(\mathrm{HP}[\mathrm{K}+, 20 \mathrm{mmol} / \mathrm{L}, \mathrm{n}$ $=31]$ ) cold blood cardioplegia group or the moderate potassium (MP $[\mathrm{K}+, 10 \mathrm{mmol} / \mathrm{L}, \mathrm{n}=37]$ ) cold blood cardioplegia group.

- Heart arresting time, rhythm recovery time, mechanical ventilation time, inotropic drug use in the intensive care unit, perioperative serum cardiac troponin I concentrations, morbidities, and mortalities were compared between the two groups.

\section{Results}

- There were no differences in cardiopulmonary bypass time, aorta cross-clamping time, cardioplegia volume, lowest body temperature during cardiopulmonary bypass, total volume of cardioplegia delivered, hematocrit value, and fluid output during the operation between the two groups.

- There was a longer arresting time and a shorter rhythm recovery time in the MP group (35.6 $\pm 2.4 \mathrm{~s}$, and $30.8 \pm 3.1 \mathrm{~s})$ when compared with that in the HP group $(24.7 \pm 2.7 \mathrm{~s}$, and $42.0 \pm 4.0 \mathrm{~s}$, both $\mathrm{p}<0.05)$. 
- The total mediastinal drainage volume, the length of stay in the intensive care unit, the postoperative inotropic drug use, and the postoperative hospital time were similar between the two groups.

- The number of patients with a long postoperative mechanical ventilation time ( $>24$ hours) in the MP group ( 6 of 36 ) was less than that in HP group (13 of $30 ; \mathrm{p}<0.05)$.

- At 1 hour, 3 hours, and 6 hours after myocardium reperfusion, the serum concentration of cardiac troponin- I significantly decreased in the MP group (in ng/mL: $15.18 \pm 3.57,24.83 \pm 4.91$, and $19.62 \pm$ 3.93 , respectively) when compared with that in the HP group (in ng/ $\mathrm{mL}: 32.67 \pm 5.31,39.26 \pm 7.43$, and $30.52 \pm 5.17$, respectively, $\mathrm{p}<0.05$ ).

\section{Conclusions}

This trial concluded that: This study showed that the Moderate potassium $(10 \mathrm{mmol} / \mathrm{L})$ cold blood cardioplegia formula is associated with better myocardial protective effects when compared with conventional High Potassium cold blood cardioplegia in pediatric patients

\section{Meta-analysis of randomized trials of effect of milrinone on mortality in cardiac surgery: an update}

This study was done by David T. Majure, MD, MPH, Teresa Greco, MSc, MStat, Massimiliano Greco, MD, Martin Ponschab, MD, Giuseppe Biondi-Zoccai, MD, Alberto Zangrillo, MD, Giovanni Landoni, MD and was published in J Cardiothorac Vasc Anesth. 2013 Apr; 27(2):220-229 [23].

\section{Objective}

- The long-term use of milrinone was associated with increased mortality in chronic heart failure.

- $\quad$ Some meta-analysis suggested that it might increase mortality in patients undergoing cardiac surgery.

- The authors conducted an updated meta-analysis of randomized trials in patients undergoing cardiac surgery to determine if milrinone impacted survival.

\section{Methods}

- This was a meta-analysis.

- One thousand thirty-seven patients from 20 randomized trials were included.

- $\quad$ Biomed, Central, PubMed, EMBASE, the Cochrane central register of clinical trials, and conference proceedings were searched for randomized trials that compared milrinone versus placebo or any other control in adult and pediatric patients undergoing cardiac surgery.

- Authors of trials that did not include mortality data were contacted.

- Only trials for which mortality data were available were included.

\section{Results}

- Overall analysis showed no difference in mortality between patients receiving milrinone versus control $(12 / 554$ [2.2\%] in the milrinone group v 10/483 [2.1\%] in the control arm; relative risk [RR] $=1.15 ; 95 \%$ confidence interval $[\mathrm{CI}], 0.55-2.43 ; p=0.7)$ or in analysis restricted to adults (11/364 [3\%] in the milrinone group v $9 / 371$ [2.4\%] in the control arm; $\mathrm{RR}=1.17 ; 95 \% \mathrm{CI}, 0.54-2.53 ; p=0.7$ ).

- $\quad$ Sensitivity analyses in trials with a low risk of bias showed a trend toward an increase in mortality with milrinone (8/153 [5.2\%] in the milrinone arm v 2/152 [1.3\%] in the control arm; $\mathrm{RR}=2.71 ; 95 \%$ CI, 0.82-9; $\mathrm{p}$ for effect $=0.10$ ).

\section{Conclusions}

This trial concluded that: Despite theoretic concerns for increased mortality with intravenous milrinone in patients undergoing cardiac surgery, the authors were unable to confirm an adverse effect on survival.

- However, sensitivity analysis of high-quality trials showed a trend toward increased mortality with milrinone.

\section{Cardioprotective effect of remote ischemic postconditioning on children undergoing cardiac surgery: a randomized controlled trial}

This trial was done by Haixing Zhong, Zijun Gao, Min Chen, Jing Zhao, Feng Wang, Liya Li, Hailong Dong, Lixin Liu, Qiang Wang, Lize Xiong and was published in Paediatr Anaesth. 2013 Aug; 23(8):726-33 [24].

\section{Background}

Remote ischemic postconditioning (RPostC) is a noninvasive intervention that has demonstrated cardioprotection and neuroprotection in animal studies.

\section{Objective}

Their goal was to investigate the cardio-cerebral protective effects of RPostC on children undergoing open-heart surgery for repair of congenital heart defects (CHD).

\section{Methods}

- Children undergoing open-heart repair of CHD were randomly assigned to a RPostC or control group.

- $\quad$ RPostC was induced by three 5-min cycles of lower limb ischemia and reperfusion using a blood pressure cuff $(200 \mathrm{mmHg})$ at the onset of aortic unclamping. Serum cardiac troponin I (cTnI), creatine kinase-MB (CK-MB), neuron-specific enolase (NSE), S100 $\beta$, cytokines, and clinical outcomes were assessed.

\section{Results}

- There were 35 children in the control group and 34 in the RPostC group.

- The mean age $(3.64 \pm 1.95$ years vs. $3.45 \pm 3.02$ years, $\mathrm{P}=0.80)$, weight $(15.11 \pm 6.91 \mathrm{~kg}$ vs. $13.40 \pm 6.33 \mathrm{~kg}, \mathrm{P}=0.37)$, surgical time (144.82 $\pm 38.51 \mathrm{~min}$ vs. $129.92 \pm 30.76 \mathrm{~min}, \mathrm{P}=0.15)$, and bypass time $(78.01 \pm 27.22 \mathrm{~min}$ vs. $72.52 \pm 26.05 \mathrm{~min}, \mathrm{P}=0.49)$ were not different.

- Compared with the control group, the postoperative levels of cTnI $(\mathrm{P}=0.037)$ and CK-MB $(\mathrm{P}=0.046)$ were significantly reduced in the RPostC group.

- The MAP was higher $(\mathrm{P}=0.008)$, and ICU stay $(36.87 \pm 3.30 \mathrm{~h}$ vs. $60.57 \pm 7.35 \mathrm{~h}, \mathrm{P}=0.006)$ and postoperative hospital stay ( $8.56 \pm 1.50$ days vs. $10.06 \pm 2.41$ days, $\mathrm{P}=0.048)$ were shorter in the RPostC group than in the control group. 
- However, the postoperative CVP and the concentrations of NSE, S100 $\beta$, CRP, TNF- $\alpha$, IL- $1 \beta$, IL- 6 , and IL- 10 were not significantly different (Table 3).

\section{Conclusion}

This trial concluded that: RPostC significantly alleviates cardiac injury in children undergoing open-heart repair of CHD and may also reduce cerebral injury.

\section{References}

1. Chowdhury D, Ojamaa K, Parnell VA, McMahon C, Sison CP, (2001) A prospective randomized clinical study of thyroid hormone treatment after operations for complex congenital heart disease. J Thorac Cardiovasc Surg 122:1023-1025.

2. McGill N, O'Shaughnessy D, Pickering R, Herbertson M, Gill R (2002) Mechanical methods of reducing blood transfusion in cardiac surgery: randomised controlled trial. BMJ 324: 1299. [Crossref]

3. Stocker C, Penny DJ, Brizard CP, Cochrane AD, Soto R, et al. (2003) Intravenous sildenafil and inhaled nitric oxide: a randomised trial in infants after cardiac surgery. Intensive Care Med 291996-2003.

4. Russell JA, Navickis RJ, Wilkes MM (2004)Albumin versus Crystalloid for Pump Priming in Cardiac Surgery: Meta-Analysis of Controlled Trials. J Cardiothorac Vasc Anesth 18: 429-437.

5. McCall MM, Blackwell MM, Smyre JT, Sistino JJ, Acsell JR, et al. (2004) Fresh frozen plasma in the pediatric pump prime: a prospective, randomized trial. Ann Thorac Surg77: 983-987.[Crossref]

6. Mackie, Booth KL, Newburger JW, Gauvreau K, Huang SA, et al. (2005)A randomized, double-blind, placebo-controlled pilot trial of triiodothyronine in neonatal heart surgery. J Thorac Cardiovasc Surg 130: 810-816.

7. Cheung KW, Green RS, Magee KD (2006) Systematic review of randomized controlled trials of therapeutic hypothermia as a neuroprotectant in post cardiac arrest patients. CJEM 8: 329-337.

8. Galiè N, Beghetti M, Gatzoulis MA, Granton J, Berger RM, et al. (2006) Bosentan therapy in patients with Eisenmenger syndrome: a multicenter, double-blind, randomized, placebo-controlled study. Circulation 114: 48-54.[Crossref]

9. Wypij D, Jonas RA, Bellinger DC, Del Nido PJ, Mayer JE, et al. (2008) The effect of hematocrit during hypothermic cardiopulmonary bypass in infant heart surgery: Results from the combined Boston hematocrit trials. J Thorac Cardiovasc Surg 135: 355-360.

10. Newburger W, Jonas RA, Soul J, Kussman BD, Bellinger DC, et al. (2008) Randomized trial of hematocrit $25 \%$ versus $35 \%$ during hypothermic cardiopulmonary bypass in infant heart surgery. $J$ Thorac Cardiovasc Surg 135: 347-354

11. Abdullah, Nihan, Yesim, Turkan, Arif, et al.(2008)Early extubation and weaning with bilevel positive airway pressure ventilation after cardiac surgery. South African Journal of AnaesthAnalg14: 25-31.

12. Preisman, Lembersky H, Yusim Y,Zilka LR, Perel A, et al. (2009) A Randomized Trial of Outcomes of Anesthetic Management Directed to Very Early Extubation after Cardiac Surgery in Children. J Cardiothoracic Vascular Anesthesia 23: 348-357.

13. Peek GJ, Mugford M, TiruvoipatiR, Wilson A, Allen E, et al. (2009) Efficacy and economic assessment of conventional ventilatory support versus extracorporeal membrane oxygenation for severe adult respiratory failure (CESAR): a multicentre randomised controlled trial. Lancet 374: 1351-1363.

14. Alghamdi AA1, Singh SK, Hamilton BC, Yadava M, Holtby H, et al. (2010) Early extubation after pediatric cardiac surgery: systematic review, meta-analysis, and evidence-based recommendations. J Card Surg 25: 586-595.[Crossref]

15. Gruenwald CE, Manlhiot C, Chan AK, Crawford-Lean L, Foreman C, et al. (2010) Randomized, Controlled Trial of Individualized Heparin and Protamine Management in Infants Undergoing Cardiac Surgery with cardiopulmonary Bypass. $J$ Am Coll Cardiol 56:1794-1802.

16. Levi M63, Levy JH, Andersen HF, Truloff D (2010) Safety of recombinant activated factor VII in randomized clinical trials. $N$ Engl J Med 363: 1791-1800.[Crossref]

17. Cappabianca G, Rotunno C, Schinosa LDLT, Ranieri M, Paparella D (2011)Protective Effects of Steroids in Cardiac Surgery: A Meta-Analysis of Randomized Double-Blind Trials. J Cardiothorac Vasc Anesth 25:156-165.

18. Monagle P, Cochrane A, Roberts R, Manlhiot C, Weintraub R, et al. (2011) A Multicenter, Randomized Trial Comparing Heparin/Warfarin and Acetylsalicylic Acid as Primary Thrombo- prophylaxis for 2 Years After the Fontan Procedure in Children. $J$ Am Coll Cardiol 58: 652-653.

19. Shimizu K, Toda Y, Iwasaki T, Takeuchi M, Morimatsu H, et al. (2011) Effect of tranexamic acid on blood loss in pediatric cardiac surgery: a randomized trial. $J$ Anesth 25: 823-830.

20. Caputo M, Patel N, Angelini GD, Siena PD, Stoica S, et al. (2012) Effect of normothermic cardiopulmonary bypass on renal injury in pediatric cardiac surgery: A randomized controlled trial. J Thorac Cardiovasc Surg 143: 758.

21. Agus MSD, Steil GM, Wypij D, Costello JM, Laussen PC, et al. (2012)Tight Glycemic Control versus Standard Care after Pediatric Cardiac Surgery. NEJM.

22. Liu Y, Zhang SL, Duan WX, Lei LP, Yu SQ, et al. (2012) The Myocardial Protective Effects of a Moderate- Potassium Blood Cardioplegia in Pediatric Cardiac Surgery: A Randomized Controlled Trial. Ann Thorac Surg 94: 1295-1301.

23. Majure DT, Greco T, Greco M, Ponschab M, Biondi-Zoccai G, et al. (2013) Metaanalysis of Randomized Trials of Effect of Milrinone on Mortality in Cardiac Surgery: An Update. J Cardiothorac Vasc Anesth 27: 220-229.

24. Zhong H, Gao Z, Chen M, Zhao J, Wang F, et al. (2013) Cardioprotective effect of remote ischemic postconditioning on children undergoing cardiac surgery: a randomized controlled trial. Paediatr Anaesth 23: 726-733.[Crossref]

Copyright: $\odot 2016$ Khan MS. This is an open-access article distributed under the terms of the Creative Commons Attribution License, which permits unrestricted use, distribution, and reproduction in any medium, provided the original author and source are credited. 